\title{
Fluoromica nanoparticle cytotoxicity in macrophages decreases with size and extent of uptake
}

This article was published in the following Dove Press journal:

International Journal of Nanomedicine

26 March 2015

Number of times this article has been viewed

\section{Nicolin Tee ${ }^{1}$ \\ Yingdong Zhu ${ }^{2}$ \\ Gysell M Mortimer' \\ Darren J Martin² \\ Rodney F Minchin'}

'School of Biomedical Science, University of Queensland, Brisbane, QLD, Australia; ${ }^{2}$ Australian Institute of Bioengineering and Nanotechnology, University of Queensland, Brisbane, QLD, Australia
Correspondence: Rodney F Minchin School of Biomedical Sciences, University of Queensland, St Lucia, Brisbane, QLD 4072, Australia

Tel +6I 73365 I894

Fax +6I 733651766

Email r.minchin@uq.edu.au
Abstract: Polyurethanes are widely used in biomedical devices such as heart valves, pacemaker leads, catheters, vascular devices, and surgical dressings because of their excellent mechanical properties and good biocompatibility. Layered silicate nanoparticles can significantly increase tensile strength and breaking strain of polyurethanes potentially increasing the life span of biomedical devices that suffer from wear in vivo. However, very little is known about how these nanoparticles interact with proteins and cells and how they might exert unwanted effects. A series of fluoromica nanoparticles ranging in platelet size from 90 to over $600 \mathrm{~nm}$ in diameter were generated from the same base material ME100 by high energy milling and differential centrifugation. The cytotoxicity of the resulting particles was dependent on platelet size but in a manner that is opposite to many other types of nanomaterials. For the fluoromicas, the smaller the platelet size, the less toxicity was observed. The small fluoromica nanoparticles $(<200 \mathrm{~nm})$ were internalized by macrophages via scavenger receptors, which was dependent on the protein corona formed in serum. This internalization was associated with apoptosis in RAW cells but not in dTHP-1 cells. The larger particles were not internalized efficiently but mostly decorated the surface of the cells, causing membrane disruption, even in the presence of $80 \%$ serum. This work suggests the smaller fluoromica platelets may be safer for use in humans but their propensity to recognize macrophage scavenger receptors also suggests that they will target the reticulo-endoplasmic system in vivo.

Keywords: layered silicates, accumulation, phagocytosis, high energy milling

\section{Introduction}

Polyurethanes are widely used in biomedical devices such as heart valves, pacemaker leads, catheters, vascular devices, and surgical dressings because of their excellent mechanical properties and good biocompatibility. ${ }^{1}$ The addition of layered silicate nanoparticles to different polyurethanes can form nanocomposites with significantly increased tensile strength and breaking strain. ${ }^{2,3}$ These nanocomposites have the potential to increase the life span of biomedical devices that suffer from wear in vivo. However, all polyurethanes exhibit some degree of biodegradation, which would lead to the release of nanoparticles at the site of implantation. Despite the growing use of layered silicates as drug delivery systems ${ }^{4,5}$ and in medical devices, ${ }^{2,3}$ very little is known about how these nanoparticles interact with proteins and cells.

It has been widely reported that the physical properties of a material can change dramatically at the nano-scale. ${ }^{6-8}$ Overt toxicity, for example, generally increases as size decreases. This has been shown for amorphous silica, ${ }^{9}$ silver, ${ }^{10}$ and metal oxides. ${ }^{11,12}$ The relationship between size and toxicity is, in part, related to the increased surface area and reactivity associated with the smaller diameter particles. ${ }^{13-15}$ Nanoparticles 
also bind to proteins that can enhance or inhibit cell binding and uptake. The accumulation of many nanoparticles into cells is central to their biodistribution and removal from the body, as well as many of their unwanted side-effects.

Macrophage cells are of particular interest as they are a major component of the foreign body reaction ${ }^{16}$ and are known to play a role in the clearance of nanoparticles from the body. ${ }^{17,18}$ While there is a number of processes by which cells can internalize nanoparticles, ${ }^{4,19,20}$ it was recently shown that layered silicate nanoparticles are taken up by human macrophages via scavenger receptor mediated phagocytosis, ${ }^{21}$ which was dependent on surface protein binding.

Synthetic fluoromicas are high aspect ratio nanoparticles that can impart important property changes to polyurethanes including increased tensile and tear strength and toughness without a significant increase in hardness or elastic modulus. ${ }^{22}$ This suggests that nanocomposites containing fluoromicas may be useful in the manufacture of implanted devices where strength and durability are essential. In the present study, a series of fluoromica nanoparticles with varying platelet sizes were generated from the same base material ME100 $0^{23-27}$ by high energy milling and differential centrifugation. These nanoparticles were then tested in human and murine cells to determine if changes in size affected toxicity and/or cell uptake.

\section{Methods}

\section{Particle preparation}

ME100 (CBC Co. Ltd, Tokyo, Japan) was dispersed in MilliQ water at $33.3 \mathrm{~g} / \mathrm{L}$ and high-energy milled in a LabStar laboratory agitator bead mill (Netzsch Group, Selb, Germany) loaded with $0.4 \mathrm{~L}$ of $0.4 \mathrm{~mm} 100 \%$ zirconium oxide beads. The mill was run at a speed of $1,250 \mathrm{rpm}$ and temperature of $33^{\circ} \mathrm{C}$ for 4 hours. The milled nanoparticles were initially centrifuged in an Allegra X-15R (Bechman Coulter Inc, Brea, CA, USA) with an SX4750 rotor at 5,250× $g$ to remove most of the large agglomerates, and then separated by differential centrifugation in an Avanti J-25I (Bechman Coulter), with $\mathrm{JA}-20$ rotor at $7,700 \times g, 17,400 \times g, 31,000 \times g$ and $48,400 \times g$. The pellet from the final centrifugation was resuspended and collected as the smallest nanoparticle fraction.

\section{Determination of particle size and surface charge}

The hydrodynamic diameter and zeta-potential of the nanoparticles were estimated by dynamic light scattering and electrophoretic light scattering, respectively (Nanosizer Nano ZS; Malvern Instruments, Malvern, UK). Aqueous dispersions of milled ME100 fractions were ultrasonicated in an ultrasonic bath for 30 minutes before use.

\section{Fourier transform infrared spectroscopy}

Fourier transform infrared spectra were recorded using a Nicolet 5700 FT-IR spectrometer (Thermo Fisher Scientific, Waltham, MA, USA) fitted with a diamond attenuated total reflection accessory. Spectra were recorded from a wavenumber of 525 to $4,000 \mathrm{~cm}^{-1}$.

\section{Scanning microscope imaging}

The nanoparticle suspension was diluted to $0.02 \mathrm{mg} / \mathrm{mL}$ and ultra-sonicated for 30 minutes. A small droplet of suspension was placed on a silicon wafer and dried in a vacuum oven for at least 7 hours at $70^{\circ} \mathrm{C}$. The sample was then splutter coated with platinum at $15 \mathrm{~mA}$ for 50 seconds (Bal-Tec MED 020; Leica Microsystems, North Ryde, NSW, Australia). Images were obtained using a JSM-7001F Field Emission scanning electron microscope (JEOL, Tokyo, Japan) at different accelerating voltages.

\section{Fluorescent labeling of nanoparticles}

The fluoromica nanoparticles were labeled by intercalation of the cyanine dye, YOYO-1 (Thermo Fisher Scientific) as previously described. ${ }^{21}$ Briefly, the dye was added at a concentration of $2 \mathrm{pmol} / \mathrm{mg}$ of nanoparticles, sonicated $(50-60 \mathrm{~Hz}$, for 10 minutes) then incubated at $4{ }^{\circ} \mathrm{C}$ for 24 hours under subdued lighting. Preliminary studies established the absence of free dye in solution and stability of the intercalated dye over the time of each experiment, as outlined elsewhere. ${ }^{21}$

\section{Cell culture}

Human acute monocytic leukemia cells (THP-1), human cervical adenocarcinoma epithelial cells (HeLa), and mouse leukemic monocyte macrophage cells (RAW 264.7) were obtained from the American Type Culture Collection (ATCC, Manassas, VA, USA) and grown at $37^{\circ} \mathrm{C}$ in a humidified $5 \% \mathrm{CO}_{2}$ atmosphere. THP-1, HeLa, and RAW cells were cultured in Roswell Park Memorial Institute 1640 (Thermo Fisher Scientific) supplemented with 5\% fetal bovine serum (FBS) and antibiotics $(50 \mathrm{U} / \mathrm{mL}$ penicillin and $50 \mu \mathrm{g} / \mathrm{mL}$ streptomycin).

Differentiation of THP-1 cells into macrophage cells (dTHP-1) was achieved by treating cells with $100 \mathrm{ng} / \mathrm{mL}$ phorbol 12-myristate 13-acetate (Sigma-Aldrich Co., St Louis, MO, USA) for 72 hours prior to the start of the experiment. HeLa and RAW cells were plated at 200,000 cells $/ \mathrm{mL}$ 16 hours prior to the beginning of the experiment to allow 
cell attachment. THP-1 cells were grown in suspension, and seeded at 500,000 cells $/ \mathrm{mL}$ immediately before beginning the experiments. When different serum conditions were required, adhesive cells were seeded and allowed to attach in 5\% FBS medium. Immediately prior to starting the experiment, this medium was removed and replaced with either serum free medium, or medium containing different concentrations of FBS.

\section{In vitro toxicity of nanoparticles}

Cell viability was assessed by CellTiter $96^{\circledR}$ AQueous One Solution Cell Proliferation Assay (Promega Corporation, Fitchburg, WI, USA) according to manufacturer's instructions. Cells were incubated in complete culture medium with nanoparticles at concentrations from $0-100 \mu \mathrm{g} / \mathrm{mL}$ for 24 hours. Time-dependent toxicity was measured after incubation with nanoparticles at $30 \mu \mathrm{g} / \mathrm{mL}$ for $1,4,8$, and 24 hours. After the incubation period, the assay solution (20 $\mu \mathrm{L} /$ well) was added directly to the wells and cells were incubated for a further 30 minutes before absorbance at $490 \mathrm{~nm}$ was measured in a POLARstar Omega microplate reader (BMG Labtech, Ortenberg, Germany). Cell free controls, used to check interference of the assay by the nanoparticles, were performed for each study.

\section{Membrane leakage assay}

Cell membrane leakage was assessed by lactate dehydrogenase (LDH) assay of cell supernatants. Nanoparticles were added to cells at $30 \mu \mathrm{g} / \mathrm{mL}$ and incubated for 4 hours. Plates were then centrifuged at $400 \times g$ for 10 minutes, $100 \mu \mathrm{L}$ of supernatant was removed and placed in a fresh, cell-free 96-well plate. LDH assay buffer (54 mM lactic acid, $0.28 \mathrm{mM}$ phenazine methosulfate, $0.66 \mathrm{mM}$ iodonitrotetrazolium violet and $1.3 \mathrm{mM}$ nicotinamide adenine dinucleotide in Tris buffer) at $\mathrm{pH} 8.2$ was added to the supernatants. Immediately after addition, absorbance at $490 \mathrm{~nm}$ was measured, and measurement was repeated every minute for 5 minutes. Cells lysed with $0.1 \%$ TritonX-100 were used as positive control.

\section{Apoptosis assay}

Apoptosis was determined using fluorescently-labeled annexin V. Although apoptotic and necrotic cells normally can be separated using membrane impermeable propidium iodide, preliminary studies indicated binding of propidium iodide to the nanoparticles, which interfered with the assay. Consequently, annexin V staining was only used with cells shown to have intact cell membranes (that is, no $\mathrm{LDH}$ release).
Cell staining was performed according to manufacturer's instructions (Dead Cell Apoptosis Kit with Annexin V Alexa Fluor $^{\circledR} 488$ and Propidium Iodide; Thermo Fisher Scientific). Briefly, cells were incubated with nanoparticles for 4 hours, then washed with phosphate buffered saline (PBS) and binding buffer. The cells were then resuspended in $100 \mu \mathrm{L}$ of binding buffer $(100,000$ cells $/ \mathrm{mL})$ and incubated with $5 \mu \mathrm{L}$ annexin $\mathrm{V}$ solution for 15 minutes on ice. Each sample was then diluted with $400 \mu \mathrm{L}$ of binding buffer and measured by flow cytometry, as described below.

\section{Uptake of nanoparticles into cells}

Association of fluorescently labeled nanoparticles with cells was assessed by flow cytometry and confocal microscopy. YOYO-1 labeled nanoparticles were incubated with cells at a concentration of $10 \mu \mathrm{g} / \mathrm{mL}$ for 4 hours. This concentration was chosen as it produced no cytotoxicity within 4 hours. Medium was then removed and the cells were washed twice with $1 \mathrm{~mL}$ of PBS. Adherent cells were detached with trypsin and gently aspirated to disaggregate cells. Cells were then transferred to round-bottom vials (BD Biosciences, San Jose, CA, USA) and diluted to a total of $1 \mathrm{~mL}$ of PBS. RAW cells were washed, as described above, then gently scraped from the surface of the culture wells, suspended in $1 \mathrm{~mL}$ of PBS by gentle aspiration and placed in round-bottom vials.

Polyinosinic acid, when used to block scavenger receptors, was added to cell culture medium at $100 \mu \mathrm{g} / \mathrm{mL}$, 60 minutes prior to addition of nanoparticles.

\section{Flow cytometry}

Samples were analyzed on a BD Biosciences FACSCanto flow cytometer (BD Biosciences, USA), controlled by BD FACSDiva v5.0.3 software (BD). Annexin V-FITC and YOYO-1 labeled nanoparticles were detected at an excitation of $488 \mathrm{~nm}$ and an emission at $530 \mathrm{~nm}$ with a slit size of $30 \mathrm{~nm}$.

\section{Confocal microscopy}

Cells were seeded onto sterile glass coverslips placed at the bottom of 12-well plates ( $2 \mathrm{~mL} /$ well) as described above. YOYO-1 labeled nanoparticles were added to the medium at a concentration of $10 \mu \mathrm{g} / \mathrm{mL}$ for 4 hours. After the incubation period, the cells were washed twice with $1 \mathrm{~mL}$ of PBS and fixed at room temperature for 30 minutes with $4 \%$ paraformaldehyde in cytoskeletal buffer $[10 \mathrm{mM} \mathrm{KCl}$, $600 \mathrm{mM}$ sucrose, $4 \mathrm{mM}$ ethylenebis(oxyethylenenitrilo) tetraacetic acid, $2 \mathrm{mM} \mathrm{MgCl}_{2}, 10 \mathrm{mM}$ piperazine-N,N'bis(2-ethanesulfonic acid)]. Fixed cells were then washed 
three times with PBS and incubated with Alexa Fluor ${ }^{\circledR}$ 555 Phalloidin $(0.165 \mu \mathrm{M}$ in PBS containing $1 \%$ bovine serum albumin) for 30 minutes. Stained cells were washed three times with PBS and then mounted onto Superfrost slides (Menzel-Gläser, Braunschweig, Germany) using Vectashield ${ }^{\circledR}$ Mounting Medium with 4',6-diamidino-2-phenylindole (DAPI) (Vector Labs Inc., Burlingame, CA, USA). Confocal images were taken on an Olympus BX61 upright confocal microscope equipped with $405 \mathrm{~nm}, 473 \mathrm{~nm}$, and $635 \mathrm{~nm}$ lasers and 430-455 nm, 490-540 nm, and 655-755 nm band pass filters (Olympus Corporation, Tokyo, Japan).

\section{One-dimensional gel electrophoresis}

Nanoparticles $(100 \mu \mathrm{g} / \mathrm{mL})$ were incubated with 5\%, 40\% or $80 \% \mathrm{FBS}$ in $\mathrm{PBS}$ at $37^{\circ} \mathrm{C}$ for 1 hour. After incubation, particles were separated by ultracentrifugation $(200,000 \times g$, 60 minutes, $4^{\circ} \mathrm{C}$, Hitachi GX series, CS120 GXL; Hitachi Ltd., Tokyo, Japan), and washed in PBS to remove unbound proteins. The nanoparticles were then mixed with $100 \mu \mathrm{L}$ of sodium dodecyl sulfate (SDS) buffer (2\% SDS, 5\% $\beta$-mercaptoethanol, 10\% glycerol, and $62.5 \mathrm{mM}$ Tris- $\mathrm{HCl}$ ) and heated to $95^{\circ} \mathrm{C}$ for 5 minutes. These protein samples (40 $\mu \mathrm{L} /$ sample) were separated on a $12 \%$ polyacrylamide gel at a constant $200 \mathrm{~V}$ for 45 minutes. Gels were stained with SyPRO ruby (Bio-Rad Laboratories, Inc., Hercules, California, USA) at room temperature overnight then washed and imaged in a ChemiDoc XRS system using Quantity One 4.5.0 software (both from Bio-Rad Laboratories Inc., Hercules, CA, USA).

\section{Statistical analysis}

All results are presented as mean \pm standard deviation, unless otherwise stated. Significance was determined at $P<0.05$ using two-tailed Student's $t$-test or one- or two-way analysis of variance (ANOVA), as required.

\section{Results}

\section{Characterization of nanoparticles}

Electron micrographs of the different milled fluoromicas are shown in Figure 1A. The unmilled ME100 particles have a high aspect ratio typical of this class of layered silicates. ${ }^{28}$ The platelets showed considerable heterogeneity in size and shape. As the particles were milled to smaller sizes, they showed greater uniformity and structure. The smallest particles (F-90) consisted primarily of nanoparticles approximately $100 \mathrm{~nm}$ in diameter, but smaller particles were also evident. The hydrodynamic diameters for each of the fractions are shown in Figure $1 \mathrm{~B}$, and were 1,000 nm, $600 \mathrm{~nm}, 250 \mathrm{~nm}, 220 \mathrm{~nm}$, and $90 \mathrm{~nm}$, respectively. These fractions will be referred to as ME100, F-600, F-250, F-220, and F-90 from largest to smallest. Some of the nanoparticle fractions were not monodispersed. This was particularly evident for the F-90 nanoparticles which showed a second population with a hydrodynamic diameter of approximately $20 \mathrm{~nm}$. Nevertheless, the milling and separation process produced four nanoparticle fractions with distinctly different size profiles.

The zeta potentials of the largest and smallest particles were compared to determine the effect of milling on surface charge (Figure S1A). The unmilled particles had a zeta potential of $-40 \pm 7.2 \mathrm{mV}$ and this increased slightly to $-30.5 \pm 0.9 \mathrm{mV}$ in the F-90 fraction. Fourier transform infrared spectroscopy was also employed to identify potential changes during milling. The spectra were similar to published data $^{27}$ and were not affected by processing (Figure S1B).

\section{Nanoparticle toxicity}

The cytotoxicity of the different nanoparticles' fractions was determined after 24 hour exposure to concentrations up to $100 \mu \mathrm{g} / \mathrm{mL}$ (Figure 2). In the two macrophage lines (dTHP-1 and RAW cells), the larger particles showed a dosedependent decrease in viability, although the murine RAW cells appear to be more sensitive. The $\mathrm{IC}_{50}$ concentrations for these particles (ME100, F-600, F-250, and F-220) ranged from 8 to $15 \mu \mathrm{g} / \mathrm{mL}$ in the dTHP-1 cells (Figure $2 \mathrm{~A}$ ) but were less than $10 \mu \mathrm{g} / \mathrm{mL}$ in the RAW cells (Figure $2 \mathrm{~B}$ ). The smallest particles (F-90) showed little toxicity in the human dTHP-1 cells and were the least toxic in the RAW cells. For comparison, non-macrophage human HeLa cells were also examined (Figure $2 \mathrm{C}$ ). The viability profiles were similar to those seen in the dTHP-1 cells, although toxicity was considerably less $\left(\mathrm{IC}_{50}=40-50 \mu \mathrm{g} / \mathrm{mL}\right)$.

The temporal changes in cell survival for each of the nanoparticles $(30 \mu \mathrm{g} / \mathrm{mL})$ are shown in Figure 3. For the larger particles, a loss in viability was seen as early as 2 hours following treatment in both macrophage cell lines. Again, little or no cytotoxicity was seen with the F-90 nanoparticles in the dTHP-1 cells. In RAW cells (Figure 3B), the F-90 nanoparticles caused cell death but at a significantly slower rate than the larger particles. By 24 hours, cell viability was similar for all particles. The difference in time-dependent toxicity for the F-90 nanoparticles suggested that cell death may result from a mechanism different to that with the larger particles. 
A

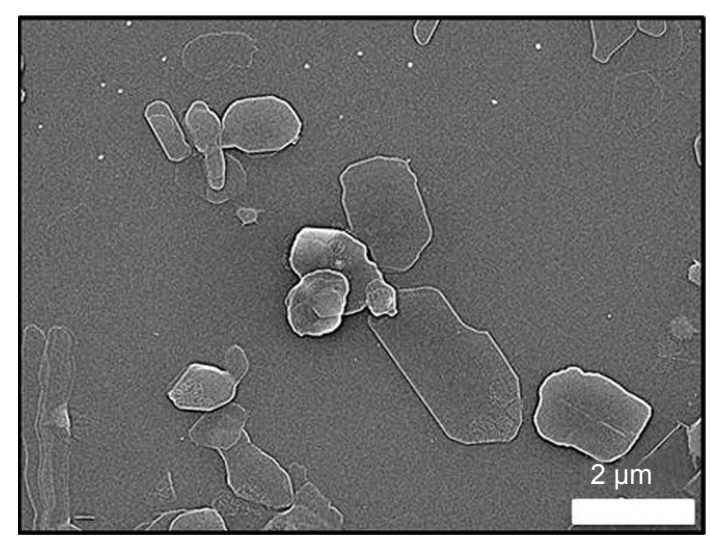

F -250

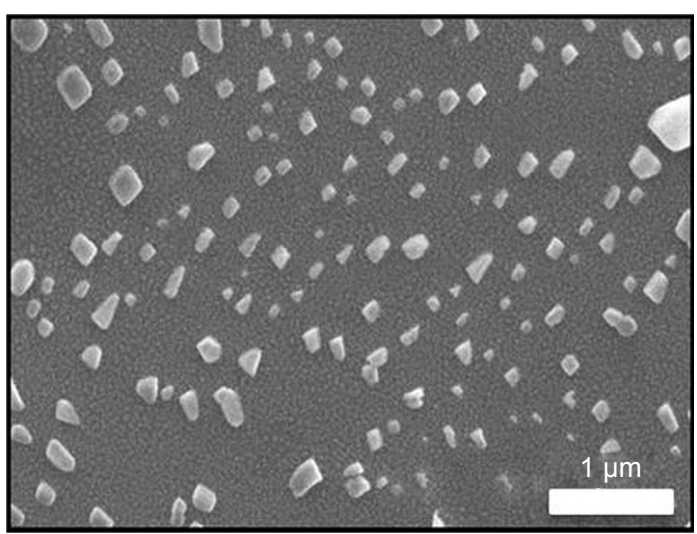

F-90

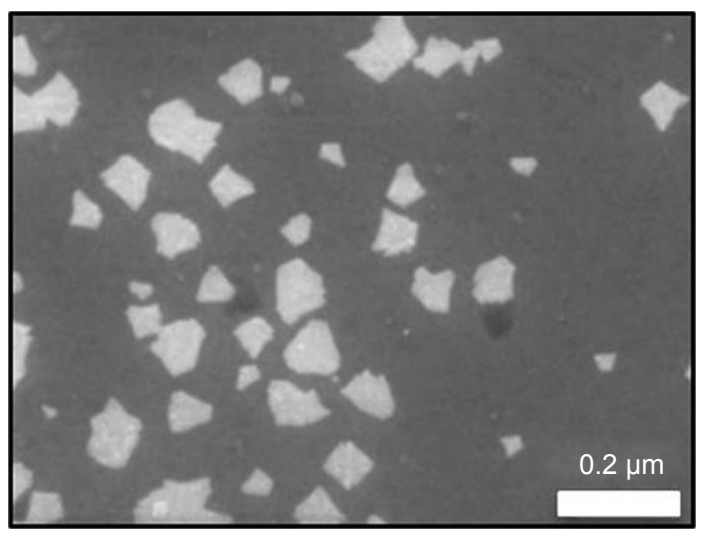

F -600

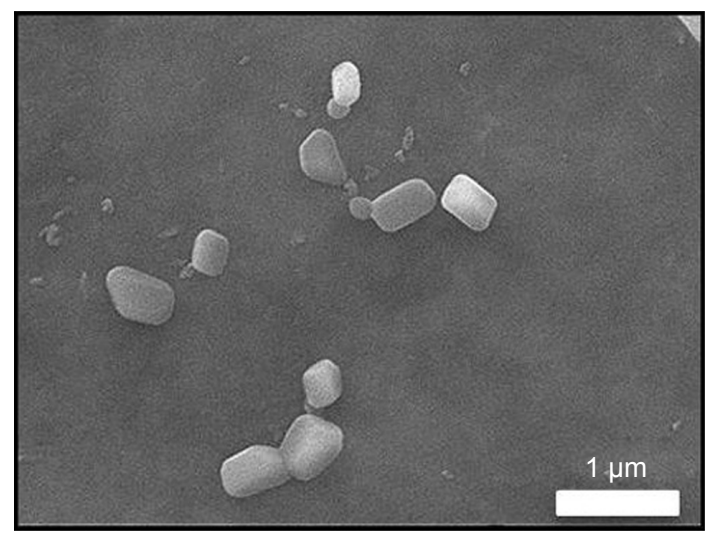

F-220

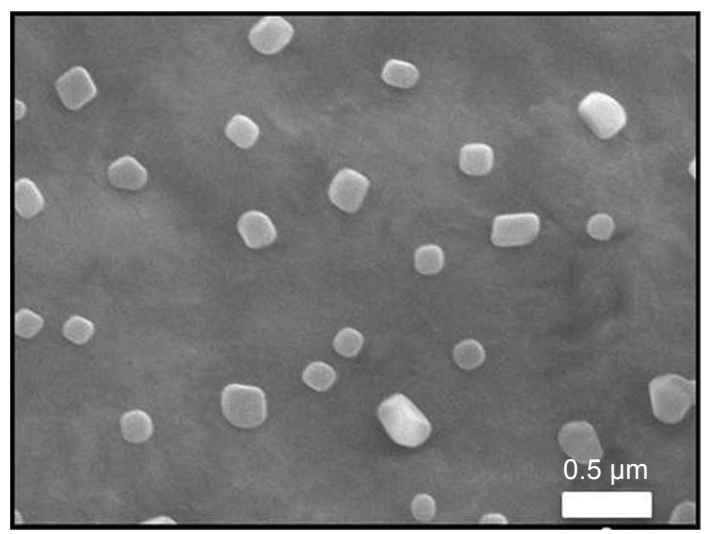

B

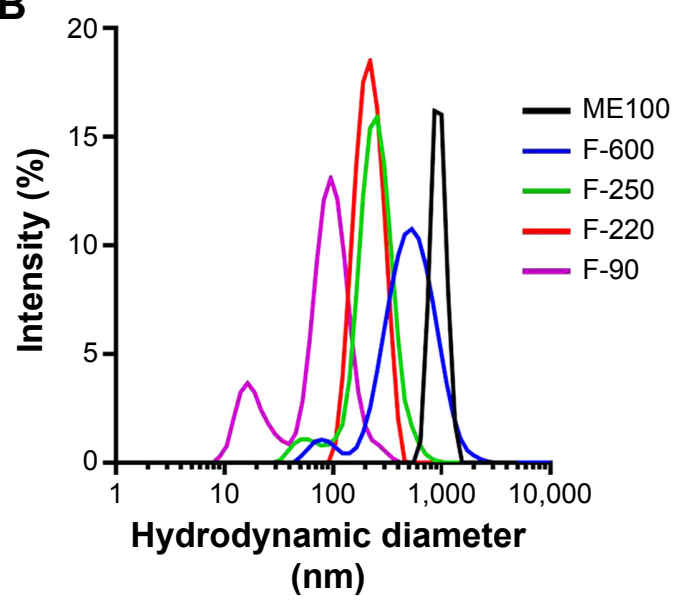

Figure I Characterization of MEI00 fractions produced by high energy milling and differential centrifugation.

Notes: (A) Scanning electron microscopy of the different particle fractions. (B) Intensity size distributions of the milled and unmilled MEI00 nanoparticles measured by dynamic light scattering.

\section{Cell membrane integrity and apoptosis}

To test whether the loss in cell viability at early time points (4 hours) resulted from membrane disruption, the release of LDH into the medium was measured. For both dTHP-1 and RAW cells, LDH release increased with increasing hydrodynamic diameter (Figure 4A), although this was more marked in the RAW cells. In the dTHP-1 cells, release was linearly related to size whereas maximal release was seen in the RAW cells for nanoparticles with a mean diameter of $250 \mathrm{~nm}$. This is similar to the decrease in viability at 4 hours 
A

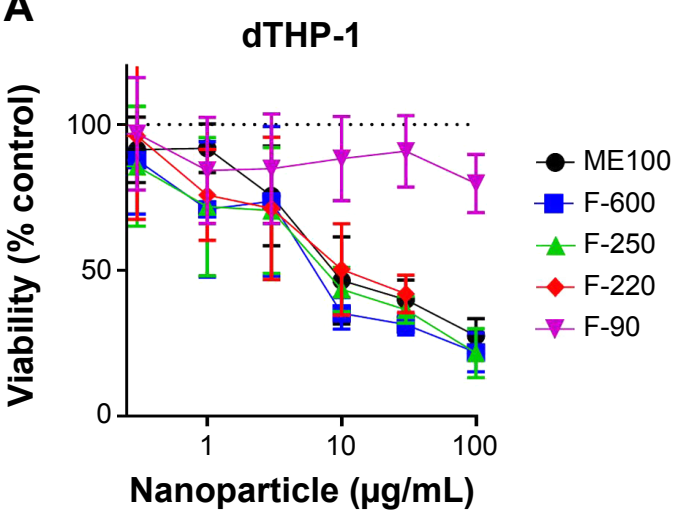

B

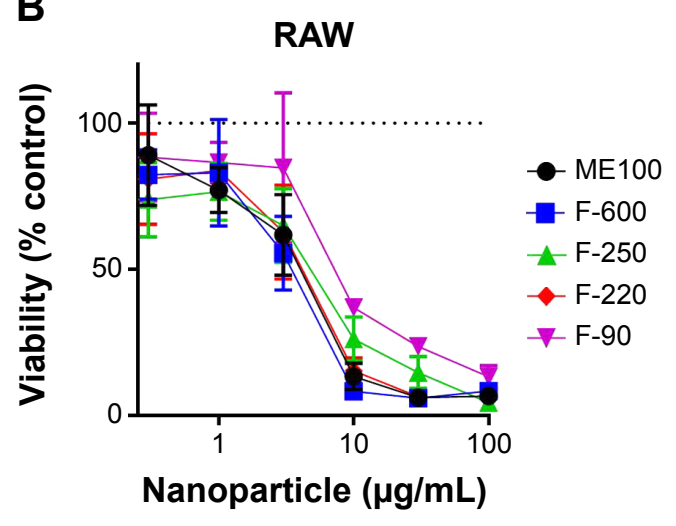

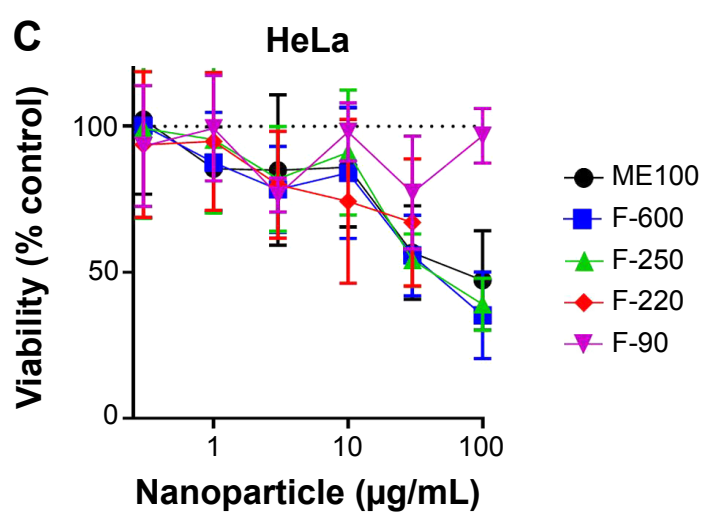

Figure 2 Concentration-dependent effects of the various nanoparticle fractions on cell viability following 24 hour exposure. Notes: (A) dTHP-I cells. (B) RAW cells. (C) HeLa cells. Results are mean \pm standard deviation $n=3$.

shown in Figure 3. The smallest nanoparticles (F-90) showed no increase in LDH release in either cell line. Consequently, induction of apoptosis by the F-90 particles $(30 \mu \mathrm{g} / \mathrm{mL})$ at 4 hours was determined by annexin V staining. In the dTHP-1 cells, there was no evidence of apoptosis (Figure 4B) consistent with the lack of cytotoxicity in this cell line. By contrast, the F-90 nanoparticles significantly increased annexin V staining in the RAW cells indicative of an apoptotic response to these particles.

\section{Nanoparticle uptake}

The uptake of the different nanoparticles was determined in dTHP-1 and RAW cells. Figure 5A shows very similar uptake for the different sized particles with the exception of
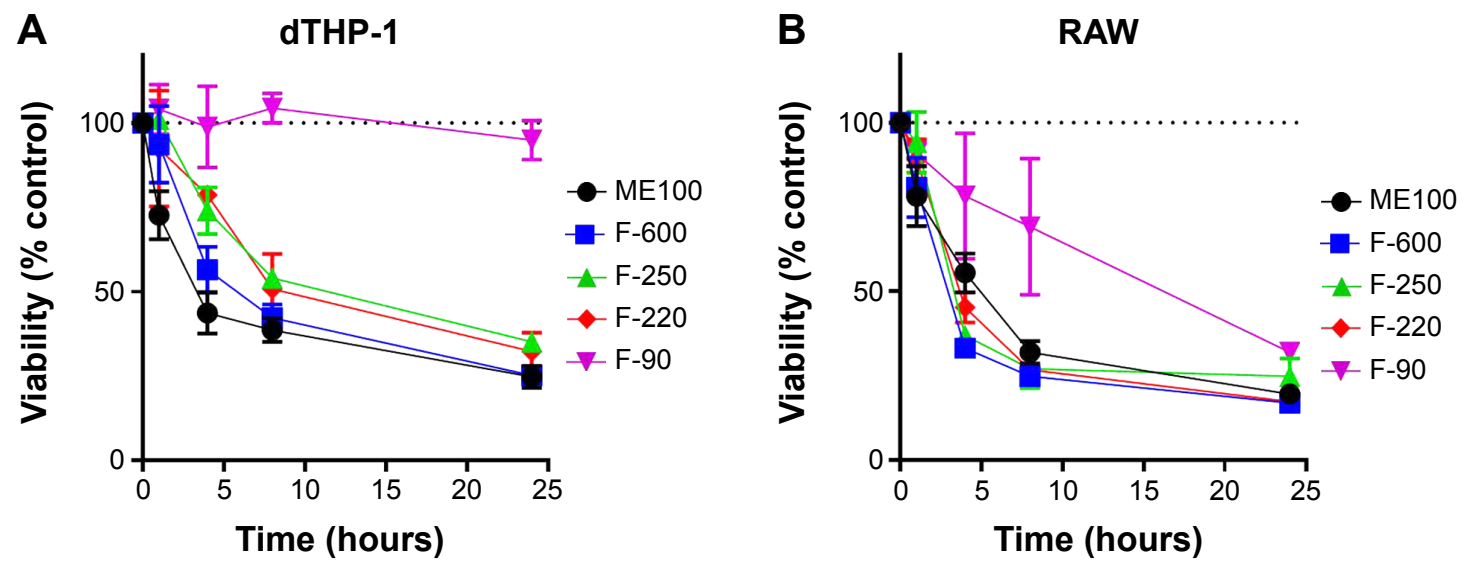

Figure 3 Time-dependent effects of the various nanoparticle fractions $(30 \mu \mathrm{g} / \mathrm{mL})$ on cell viability. Notes: (A) dTHP-I cells. (B) RAW cells. Results are mean \pm standard deviation $n=3$. 
A

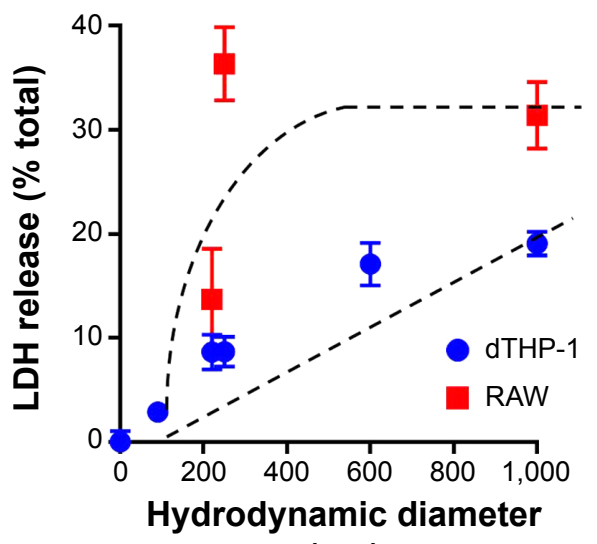

$(\mathrm{nm})$
B

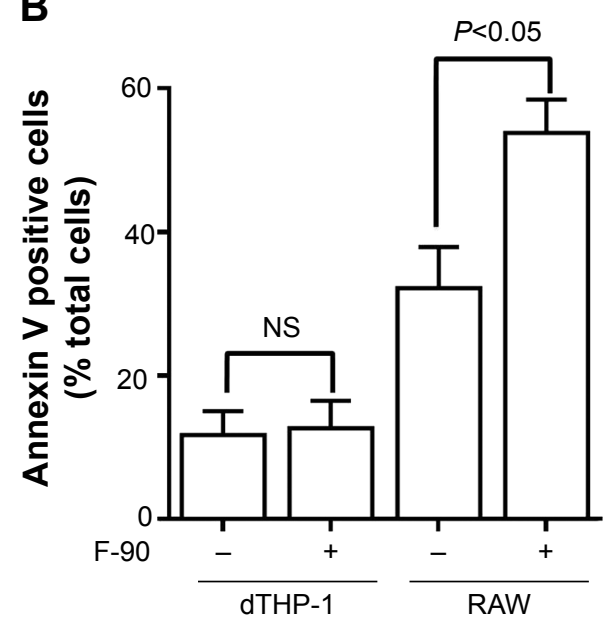

Figure 4 Membrane integrity and cell apoptosis following nanoparticle exposure.

Notes: (A) dTHP-I and RAW cells were treated with $30 \mu \mathrm{g} / \mathrm{mL}$ nanoparticles for 4 hours. Data are plotted as percent total lactate dehydrogenase (determined with I\% TritionX-100) versus the mean hydrodynamic diameter for each fraction. (B) Apoptotic cells following treatment with $30 \mu \mathrm{g} / \mathrm{mL}$ nanoparticles for 4 hours determined by annexin $V$ staining. Results are mean \pm standard deviation $n=3$. Statistical comparisons were performed using a Student's $t$-test.

Abbreviations: LDH, lactate dehydrogenase; NS, not significant.

A

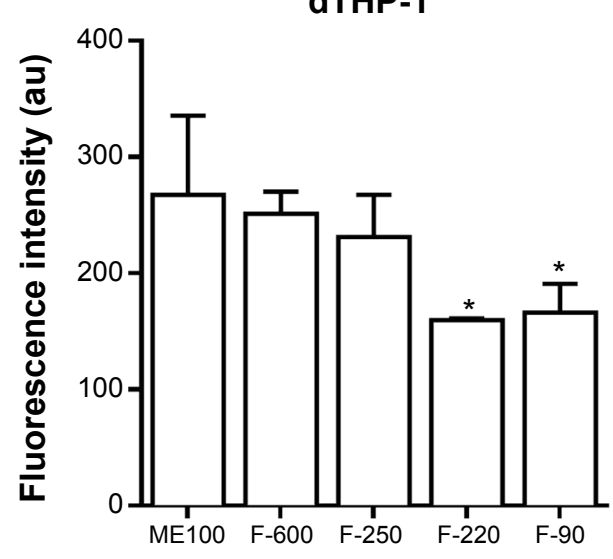

RAW
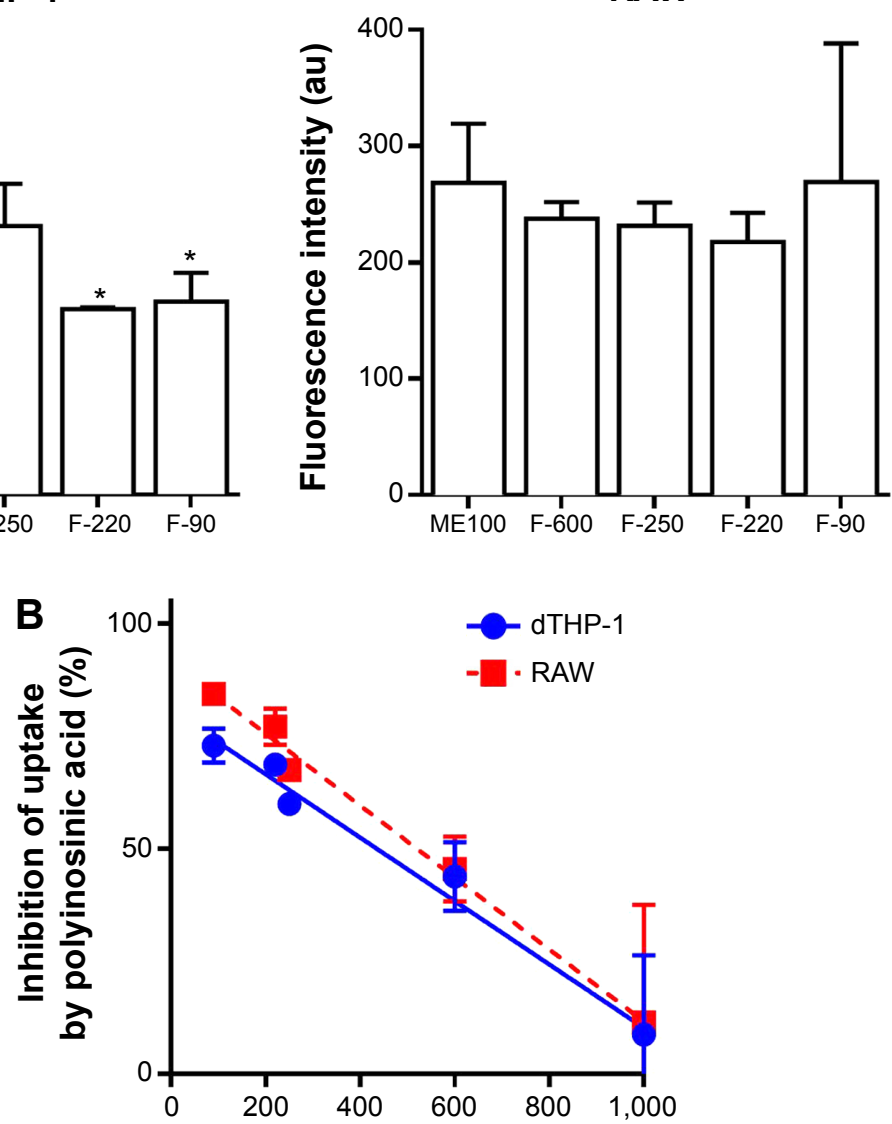

Hydrodynamic diameter ( $\mathrm{nm})$

Figure 5 Uptake of nanoparticles by dTHP-I and RAW cells.

Notes: (A) YOYO-I labeled nanoparticles $(10 \mu \mathrm{g} / \mathrm{mL})$ were incubated with each cell line in complete medium for 4 hours. Total cell-associated fluorescence was determined by flow cytometry. Results are mean \pm standard deviation $n=3$. *Indicates significantly different to MEI00. (B) Effect of polyinosinic acid on cell uptake of each nanoparticle fraction. Results are mean \pm standard deviation; $n=3$ where control cells were those not treated with polyinosinic acid.

Abbreviation: au, arbitrary units. 
the F-220 and F-90 nanoparticles, which showed slightly less uptake in dTHP-1 cells compared to the larger particles (Figure 5A, left panel). Previously, we have shown that layered silicate nanoparticles can be taken up into macrophages via the scavenger receptor. ${ }^{21}$ To test this possibility with the fluoromicas, we pretreated cells with polyinosinic acid, a broad inhibitor of scavenger receptors. Figure 5B shows that the degree of inhibition of uptake by polyinosinic acid increased as the mean hydrodynamic diameter decreased, with more than $75 \%$ inhibition of the F-90 nanoparticle uptake but less than $10 \%$ inhibition of the unmilled ME100 particle uptake. This was consistent for both cell types.

We next examined cell association of the largest and smallest particles by confocal microscopy (Figure 6). There were clear differences for the different particles. The ME100 particles were found mostly associated with the cell membrane with little evidence of internalization. By contrast, the F-90 nanoparticles were almost entirely associated with intracellular vesicles. These observations are consistent with the effects of polyinosinic acid in Figure 5B and suggest that the smaller particles are extensively internalized by both dTHP-1 cells and RAW cells. Moreover, this internalization most likely involves scavenger receptors since it was inhibited by polyinosinic acid.

\section{Binding of protein to nanoparticles}

Cell surface recognition of nanoparticles is often dependent on the type of proteins associated with the corona that forms in biological fluids such as plasma. ${ }^{29}$ Therefore, we next examined the pattern of serum protein binding to the largest (ME100) and smallest (F-90) particles in the presence of increasing serum concentration (Figure 7). The total bound protein was similar for both particles. The banding patterns were also similar, although there were significant differences
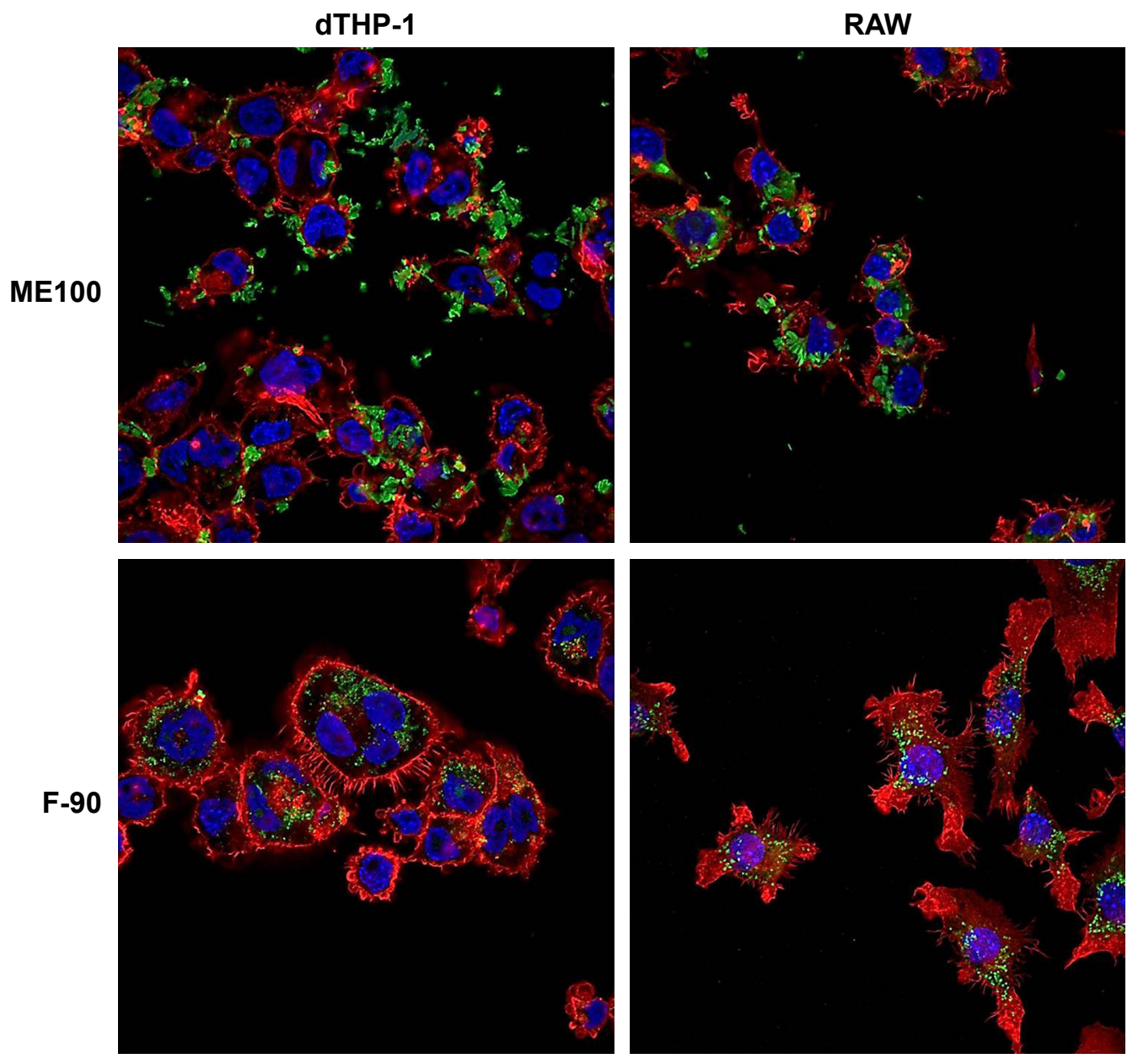

Figure 6 Confocal microscopy of dTHP-I and RAW cells exposed to MEI00 or F-90 nanoparticles (I0 $\mu \mathrm{g} / \mathrm{mL})$ for 4 hours.

Notes: Green: YOYO-I labeled nanoparticles; red: phalloidin; blue: DAPI.

Abbreviation: DAPI, 4',6-diamidino-2-phenylindole. 


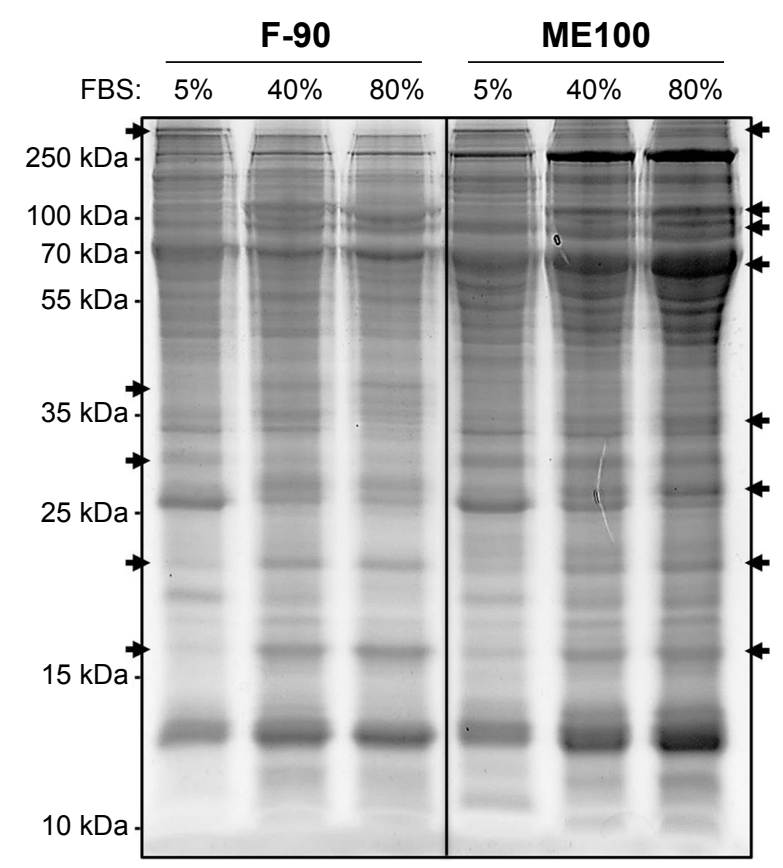

Figure 7 Protein binding to MEI00 and F-90 nanoparticles.

Notes: Nanoparticles were incubated with $5 \%, 40 \%$, and $80 \%$ fetal bovine serum (FBS) for I hour at $37^{\circ} \mathrm{C}$ and then washed to remove low affinity proteins. Bound proteins were then extracted in SDS-PAGE reducing buffer. Equal volumes of the SDS buffer were loaded in each lane. Following development, the gel was stained with SyPRO ruby. Arrows indicate proteins that change with increasing serum concentration. Abbreviation: SDS-PAGE, sodium dodecyl sulfate polyacrylamide gel electrophoresis.

within each particle as the serum concentration increased (Figure 7, arrows). This indicates that the composition of the protein corona varied between low and high serum concentrations.

\section{Effect of serum concentration on nanoparticle uptake and toxicity}

Since altering the serum concentration induced changes in the protein corona associated with the different fluoromica nanoparticles, we next asked whether this affected either cell uptake or toxicity in dTHP-1. For both ME100 and F-90 nanoparticles $(10 \mu \mathrm{g} / \mathrm{mL})$, there was no difference in uptake with the different serum concentrations (Figure 8A). Similar to the results in Figure 5B, polyinosinic acid did not inhibit the uptake of ME100 at any serum concentration. By contrast, polyinosinic acid significantly decreased the uptake of F-90 nanoparticles in the presence of $5 \%$ or $80 \%$ serum, but not in the absence of serum (Figure 8A). These data indicate that serum proteins were necessary for scavenger receptor recognition by the F-90 particles.

Serum concentration also affected the toxicity of the different fluoromicas. At 5\% serum, the ME100 particles
(30 $\mu \mathrm{g} / \mathrm{mL}$ ) induced a rapid decrease in cell viability while the F-90 nanoparticles did not. This was consistent with the data in Figure 3A. At 80\% serum, toxicity of ME100 was still evident, but significantly diminished. By contrast, the F-90 nanoparticles showed little or no toxicity in 5\% and $80 \%$ serum, but decreased cell viability in the absence of serum (Figure 8B, right panel).

\section{Discussion}

Synthetic fluoromicas are high aspect layered silicates that have been extensively studied as nanofillers in polymeric composites. The nanofiller can enhance the mechanical properties of the composite by direct interaction with the polymer chains..$^{30,31}$ Moreover, these composites have been studied as potential components in medical implants, and as drug delivery systems. ${ }^{32,33}$ Consequently, as part of their safety evaluation, human exposure to fluoromica nanoparticles requires an understanding of their potential biological interactions and adverse effects. Here, we show using a series of synthetic fluoromica nanoparticles formed by high energy milling of the same base product (ME100), that these nanoparticles behave differently to many other nanoparticles when exposed to phagocytic cells.

Size has a clear effect on the uptake and toxicity of the fluoromica nanoparticles in both human and murine macrophages. The larger nanoparticles showed greater toxicity, causing rapid membrane disruption and cell death as early as 4 hours of exposure. Conversely, the smallest (F-90) nanoparticles displayed very little toxicity in dTHP-1 cells and were significantly less toxic than the larger particles in RAW cells. These findings are in contrast to studies of other nano-sized particles where increased toxicity has been associated with a decrease in size. ${ }^{5,9,12,34,35}$ Generally, the higher surface area is cited as the likely cause of increasing toxicity. A major difference between many of the nanoparticles previously studied and the fluoromicas is their aspect ratio. This is the ratio of their diameter to their thickness. Fluoromicas, and most other clays, are very thin platelets with a thickness less than $10 \mathrm{~nm}$. It would be interesting for future studies to address the relationship between aspect ratio, internalization, and cytotoxicity in a series of particles derived from the same material.

A major difference between the different fluoromica particles was the ability of the smallest particles to be internalized by both dTHP-1 and RAW cells by scavenger receptor mediated phagocytosis. The larger particles primarily decorated the cell surface. Phagocytosis was dependent 

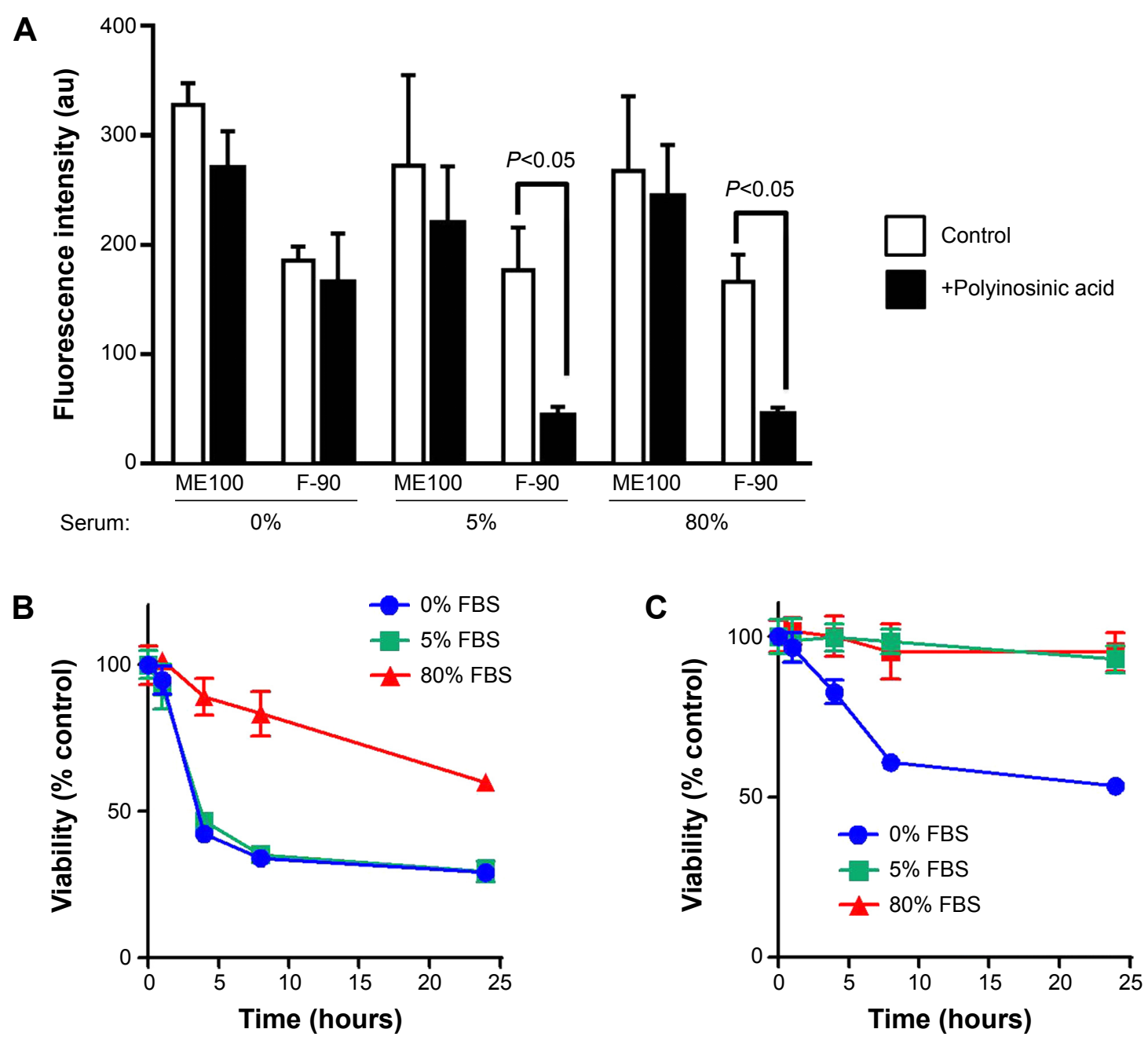

Figure 8 Effect of serum on uptake and toxicity of nanoparticle fractions.

Notes: (A) Uptake of YOYO-I labeled MEI00 and F-90 nanoparticles ( $10 \mu \mathrm{g} / \mathrm{mL})$ with increasing serum concentrations in dTHP-I cells. Open bars: controls; closed bars: cells pretreated with polyinosinic acid. Time-dependent toxicity of MEI00 (B) and F-90 (C) nanoparticles in dTHP-I cells in different concentrations of serum. Results are mean \pm standard deviation $\mathrm{n}=3$.

Abbreviations: au, arbitrary units; FBS, fetal bovine serum.

on serum proteins, which is a similar observation to that reported for hectorite, another layered silicate nanoparticle that is internalized by macrophages. ${ }^{21}$ In those studies, albumin was shown to unfold revealing a cryptic epitope that was recognized by Class A scavenger receptors. It was not the purpose of the current study to clearly define the internalization process for the fluoromica nanoparticles, and further studies will address the similarities or differences in how macrophages might handle different layered silicate nanoparticles intended for human use.

The fluoromica nanoparticles induced cell death by different mechanisms dependent on their size. The larger particles directly damaged the cell membrane leading to a rapid release of $\mathrm{LDH}$. This was proportional to size in the dTHP-1 cells. RAW cells were significantly more sensitive to the fluoromicas with maximum membrane damage seen with the F-250 particles. While both cell types have common macrophage properties, they differ significantly in their membrane composition. For example, dTHP-1 cells express CAV1 whereas RAW cells do not. ${ }^{36}$ In addition, there are higher levels of cholesterol associated with the caveolae in dTHP-1 cells. The disruption of the cell membrane was partially, but not completely, abrogated by the protein corona formed when the nanoparticles were incubated with serum. By contrast, the F-90 nanoparticles showed little cytotoxicity in the human dTHP-1 cells although they induced apoptosis in the murine RAW cells. Several studies have demonstrated an apoptotic response in macrophages following scavenger receptor activation by nanoparticles. ${ }^{37-39}$ For silica nanoparticles, activation of CASP1 was essential for apoptosis ${ }^{40}$ while CASP9 appeared to be involved in scavenger receptor mediated apoptosis by multi-walled carbon nanotubes. ${ }^{41}$ 
These results suggest multiple pathways that nanoparticles may use to induce apoptosis in cells such as macrophages.

\section{Conclusion}

The cytotoxicity of synthetic fluoromicas is dependent on the nanoparticle platelet size but in a manner that is opposite to many other types of nanomaterials. These findings provide initial evidence that smaller fluoromica nanoparticles may be safer for use in humans but their propensity to recognize macrophage scavenger receptors also suggests that they are likely to target the reticulo-endoplasmic system in vivo. This may be advantageous for fluoromicas that escape from medical implants or other devices where clearance is desirable, but suggests they would be of limited use in drug delivery or tissue targeting in vivo.

\section{Disclosure}

The authors declare no conflicts of interest with respect to the authorship and/or publication of this article.

\section{References}

1. Santerre JP, Woodhouse K, Laroche G, Labow RS. Understanding the biodegradation of polyurethanes: from classical implants to tissue engineering materials. Biomaterials. 2005;26(35):7457-7470.

2. Finnigan B, Casey P, Cookson D, et al. Impact of controlled particle size nanofillers on the mechanical properties of segmented polyurethane nanocomposites. Int J Nanotech. 2007;4(5):496-515.

3. Osman AF, Edwards GA, Schiller TL, et al. Structure-Property Relationships in Biomedical Thermoplastic Polyurethane Nanocomposites. Macromolecules. 2012;45(1):198-210.

4. Dizman B, Badger JC, Elasri MO, Mathias LJ. Antibacterial fluoromicas: A novel delivery medium. Applied Clay Science. 2007;38(1-2):57-63.

5. Park JK, Choy YB, Oh JM, Kim JY, Hwang SJ, Choy JH. Controlled release of donepezil intercalated in smectite clays. Int J Pharm. 2008; 359(1-2):198-204.

6. Buffat P, Borel JP. Size effect on the melting temperature of gold particles. Physical Rev A. 1976;13(6):2287-2298.

7. El-Sayed MA. Small Is Different: Shape-, Size-, and CompositionDependent Properties of Some Colloidal Semiconductor Nanocrystals. Acc Chem Res. 2004;37(5):326-333.

8. Jiang W, Kim BYS, Rutka JT, Chan WC. Nanoparticle-mediated cellular response is size-dependent. Nature Nanotechnology. 2008;3(3): $145-150$

9. Napierska D, Thomassen LC, Rabolli V, et al. Size-Dependent Cytotoxicity of Monodisperse Silica Nanoparticles in Human Endothelial Cells. Small. 2009;5(7):846-853.

10. Yang EJ, Kim S, Kim JS, Choi IH. Inflammasome formation and IL-1 $\beta$ release by human blood monocytes in response to silver nanoparticles. Biomaterials. 2012;33(28):6858-6867.

11. Gurr JR, Wang AS, Chen CH, Jan KY. Ultrafine titanium dioxide particles in the absence of photoactivation can induce oxidative damage to human bronchial epithelial cells. Toxicology. 2005;213(1-2):66-73.

12. Midander K, Cronholm P, Karlsson HL, et al. Surface Characteristics, Copper Release, and Toxicity of Nano- and Micrometer-Sized Copper and Copper(II) Oxide Particles: A Cross-Disciplinary Study. Small. 2009;5(3):389-399.

13. Duffin R, Tran L, Brown D, Stone V, Donaldson K. Proinflammogenic effects of low-toxicity and metal nanoparticles in vivo and in vitro: highlighting the role of particle surface area and surface reactivity. Inhal Toxicol. 2007;19(10):849-856.
14. Rabolli V, Thomassen LC, Princen C, et al. Influence of size, surface area and microporosity on the in vitro cytotoxic activity of amorphous silica nanoparticles in different cell types. Nanotoxicology. 2010;4(3): 307-318.

15. Stone V, Johnston H, Schins RP. Development of in vitro systems for nanotoxicology: methodological considerations. Crit Rev Toxicol. 2009;39(7):613-626.

16. Anderson JM, Rodriguez A, Chang DT. Foreign body reaction to biomaterials. Semin Immunol. 2008;20(2):86-100.

17. Geiser M. Update on Macrophage Clearance of Inhaled Micro- and Nanoparticles. J Aerosol Med Pulmon Drug Delivery. 2010;23(4): 207-217.

18. Semmler-Behnke M, Takenaka S, Fertsch S, et al. Efficient Elimination of Inhaled Nanoparticles from the Alveolar Region: Evidence for Interstitial Uptake and Subsequent Reentrainment onto Airways Epithelium. Environ Health Perspect. 2007;115(5):728-733.

19. Iversen TG, Skotland T, Sandvig K. Endocytosis and intracellular transport of nanoparticles: Present knowledge and need for future studies. Nano Today. 2011;6(2):176-185.

20. Zhao F, Zhao Y, Liu Y, Chang X, Chen C, Zhao Y. Cellular Uptake, Intracellular Trafficking, and Cytotoxicity of Nanomaterials. Small. 2011; 7(10):1322-1337.

21. Mortimer GM, Butcher NJ, Musumeci AW, Deng ZJ, Martin DJ, Minchin RF. Cryptic epitopes of albumin determine mononuclear phagocyte system clearance of nanomaterials. ACS Nano. 2014; 8(4):3357-3366.

22. Zilg C, Thomann R, Mulhaupt R, Finter J. Polyurethane nanocomposites containing laminated anisotropic nanoparticles derived from organophilic layered silicates. Advanced Materials. 1999;11(1):49-52.

23. Cattaneo AS, Bracco S, Comotti A, Galimberti M, Sozzani P, Eckert H. Structural Characterization of Pristine and Modified Fluoromica Using Multinuclear Solid-State NMR. J Phys Chem C. 2011;115(25):12517-12529.

24. Gelfer MY, Burger C, Nawani P, et al. Lamellar nanostructure in 'Somasif'-based organoclays. Clays Clay Miner. 2007;55(2):140-150.

25. Hussain SM, Hess KL, Gearhart JM, Geiss KT, Schlager JJ. In vitro toxicity of nanoparticles in BRL 3A rat liver cells. Toxicol In Vitro. 2005;19(7):975-983.

26. Lagaly $\mathrm{G}$, Beneke $\mathrm{K}$. Intercalation and exchange reactions of clay minerals and non-clay layer compounds. Colloid and Polymer Science. 1991;269(12):1198-1211.

27. Souza DH, Dahmouche K, Andrade CT, Dias ML. Structure, morphology and thermal stability of synthetic fluorine mica and its organic derivatives. Applied Clay Science. 2011;54(3-4):226-234.

28. Kloprogge JT, Komarneni S, Amonette JE. Synthesis of smectite clay minerals: a critical review. Clays Clay Miner. 1999;47(5):529-554.

29. Monopoli MP, Aberg C, Salvati A, Dawson KA. Biomolecular coronas provide the biological identity of nanosized materials. Nat Nanotechnol. 2012;7(12):779-786.

30. Finnigan B, Martin D, Halley P, Truss R, Campbell K. Morphology and properties of thermoplastic polyurethane composites incorporating hydrophobic layered silicates. J Appl Polym Sci. 2005;97(1): 300-309.

31. Hiroi R, Tanaka H. A New Nanofiller to Improve the Friction and Wear Properties of PPS. J Phys Conf Ser. 2010:258:012016.

32. Campbell KT, Craig DQ, McNally T. Ibuprofen-loaded poly(epsiloncaprolactone) layered silicate nanocomposites prepared by hot melt extrusion. J Mater Sci Mater Med. 2010;21(8):2307-2316.

33. Campbell K, Qi S, Craig DQ, McNally T. Paracetamol-loaded poly(epsilon-caprolactone) layered silicate nanocomposites prepared using hot-melt extrusion. J Pharm Sci. 2009;98(12):4831-4843.

34. Papageorgiou I, Brown C, Schins R, et al. The effect of nano- and micron-sized particles of cobalt-chromium alloy on human fibroblasts in vitro. Biomaterials. 2007;28(19):2946-2958

35. Park MV, Neigh AM, Vermeulen JP, et al. The effect of particle size on the cytotoxicity, inflammation, developmental toxicity and genotoxicity of silver nanoparticles. Biomaterials. 2011;32(36):9810-9817. 
36. Matveev S, van der Westhuyzen DR, Smart EJ. Co-expression of scavenger receptor-BI and caveolin-1 is associated with enhanced selective cholesteryl ester uptake in THP-1 macrophages. J Lipid Res. 1999; 40(9):1647-1654.

37. Chao SK, Hamilton RF, Pfau JC, Holian A. Cell Surface Regulation of Silica-Induced Apoptosis by the SR-A Scavenger Receptor in a Murine Lung Macrophage Cell Line (MH-S). Toxicol Appl Pharmacol. 2001; 174(1):10-16.

38. DeVries-Seimon T, Li Y, Yao PM, et al. Cholesterol-induced macrophage apoptosis requires ER stress pathways and engagement of the type A scavenger receptor. J Cell Biol. 2005;171(1):61-73.
39. Obot CJ, Morandi MT, Beebe JT, Hamilton JR, Holian A. Surface Components of Airborne Particulate Matter Induce Macrophage Apoptosis through Scavenger Receptors. Toxicol Appl Pharmacol. 2002; 184(2):98-106.

40. Iyer R, Hamilton RF, Li L, Holian A. Silica-induced apoptosis mediated via scavenger receptor in human alveolar macrophages. Toxicol Appl Pharmacol. 1996;141(1):84-92.

41. Wang X, Guo J, Chen T, et al. Multi-walled carbon nanotubes induce apoptosis via mitochondrial pathway and scavenger receptor. Toxicol In Vitro. 2012;26(6):799-806. 


\section{Supplementary material}

A

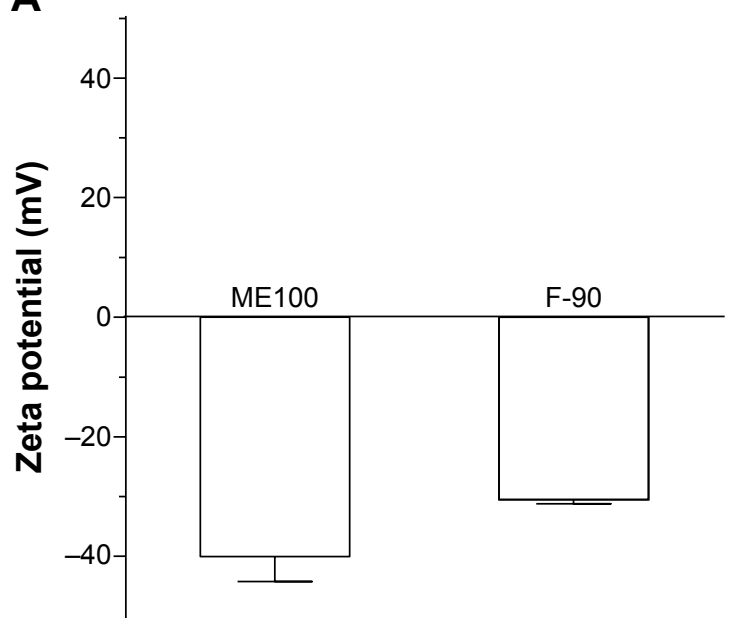

B

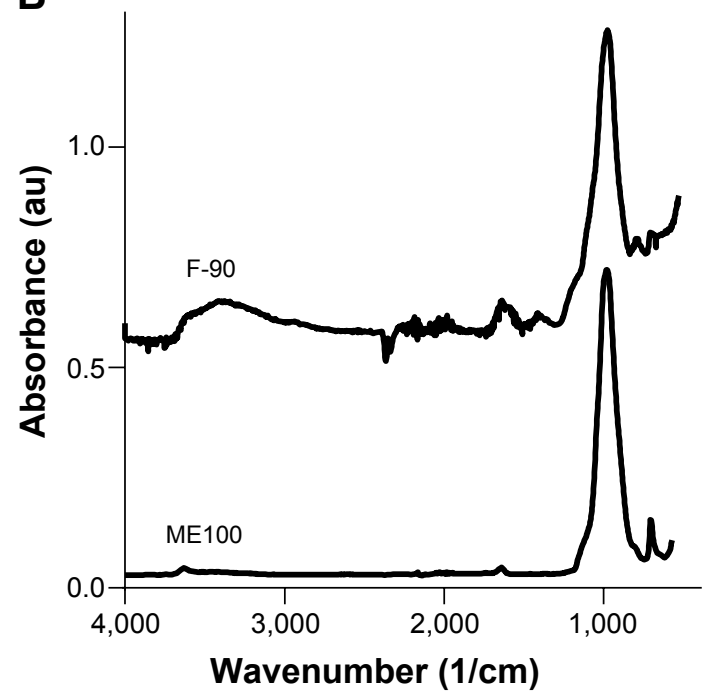

Figure SI Zeta potential (A) and FTIR spectra (B) for the largest (MEI00) and smallest (F-90) particles.

Note: Zeta potentials are plotted as mean $\pm S E M, n=3$.

Abbreviations: au, arbitrary units; FTIR, fourier transform infrared; SEM, standard error of the mean.

\section{Publish your work in this journal}

The International Journal of Nanomedicine is an international, peerreviewed journal focusing on the application of nanotechnology in diagnostics, therapeutics, and drug delivery systems throughout the biomedical field. This journal is indexed on PubMed Central, MedLine, CAS, SciSearch ${ }^{\circledR}$, Current Contents ${ }^{\circledR} /$ Clinical Medicine,
Journal Citation Reports/Science Edition, EMBase, Scopus and the Elsevier Bibliographic databases. The manuscript management system is completely online and includes a very quick and fair peer-review system, which is all easy to use. Visit http://www.dovepress.com/ testimonials.php to read real quotes from published authors. 